\title{
Intelligent Model Based Imbalance Fault Detection and Identification System of a Turbocharger Based on Vibration Analysis
}

\author{
Muchemi Gathua $^{1^{*}}$, Eng. Prof. John Kihiu², Eng. Dr. Kenneth Njoroge ${ }^{3}$, Eng. Dr. James Kimotho ${ }^{2}$. \\ 1. School of Engineering, Technical University of Mombasa (TUM), P.O. Box 90420-080100, Mombasa, \\ Kenya. \\ 2. School of Material and Mechanical Engineering, Jomo Kenyatta University of Agriculture and Technology \\ (JKUAT), Nairobi, Kenya. \\ 3. Department of Mechanical Engineering, University of Nairobi (UON), P.O. Box 30197, 00100, Nairobi, \\ Kenya. \\ *Email of the Corresponding author: gathuacharlesmuchemi@tum.ac.ke
}

The research is financed jointly by TUM and Self. The content contained herein is my original work.

\begin{abstract}
Inappropriate fault detection of turbocharger's operating parameters has generated unnecessary economic loss due to unplanned down-time. This results to a combination of late and inaccurate diagnosis of the turbocharger faults by the employed maintenance systems. This study, used a Model-based fault diagnosis approach to identify imbalance fault in a turbocharger rotor system. In this approach, the generalized theoretical equation of motion for both healthy and faulty system models of a complete turbocharger rotor, were developed using the Finite element method. A test rig for the turbocharger rotor with sensors to monitor its dynamic behavior under the influence of the aforementioned faulty condition was also developed. Following Modal Expansion, curve fitting technique was used to minimize the error between a set of equivalent experimental and numerical results.

From the results, the theoretical Frequency response functions developed from Finite Element Method fault models had good agreement with the Time and frequency-based responses measured from experimental data for the induced imbalance fault condition, hence, validating the theoretical fault models developed in this study. Using Modal Expansion technique, data from nodal residual forces generated from the developed numerical fault model was compared with measured corresponding experimental nodal residual forces data. The results showed good agreement between the theoretical and experimental findings. Hence, the Model based fault identification scheme implemented in this study successfully identified the magnitude, severity and exact location of imbalance faulty conditions.
\end{abstract}

Keywords: Model based, fault detection and identification, Turbocharger, vibration, Modal expansion, Test rig, Imbalance, modelling.

DOI: $10.7176 /$ ISDE/12-2-06

Publication date: August $30^{\text {th }} 2021$

\section{Introduction}

Power generation in Kenya or in any other developing country is vital to the nation's industrial development. A significant part of this power is generated by turbocharged marine diesel generators whose reliability and availability depend largely on the smooth operation of the engines' turbochargers. Turbochargers enhance the efficiency of internal combustion engines by providing the engines with an optimized air mass flow rate. In addition, the application of turbochargers reduces the emission of the exhaust gases. According to Miller (2008), the major advantage of the turbocharger (TC) is that the output power and torque of the engine can be significantly improved without increasing the displacement. Most of turbocharger failures are related to their lubrication which contributes up to $50 \%$ of the reported failure cases (Adamkiewicz and Michalec, 2000). On the other hand, Alignment imperfections contributing imbalance and rub impact contribute approximately (8\%) failure cases.

Inappropriate fault detection of turbochargers operating parameters has generated unnecessary economic loss due to unplanned down-time mainly resulting from turbocharger malfunctions and damages (Wakiru et al., 2018). Conventional maintenance methods for engine turbochargers employed in the power industry depend on bearings clearances checks between rotor shaft and bearing housing. In addition, some parts of the turbocharger 
have to be checked on the special stands. This results into combination of late and inaccurate diagnosis of the turbo-charger's faults by the maintenance systems employed in the respective power generating companies. Hence, it is necessary to develop an in-situ performance testing and failure prediction system for turbochargers based on vibration analysis of the equipment using the Model-based fault detection and identification (FDI) approach. This system will check if the specific parameters of turbocharger dynamic behavior have reached critical levels without stopping and dismantling the turbocharger unit, and it will also inform the personnel involved of the nature of the fault with respect to its type, location, and magnitude. The fault investigated in the present work was TC rotor imbalance.

Model-based diagnostics uses a model of the system that take into account process and system parameters in the diagnostic to analyze performance (Sharma, Dewan and Chatterji, 2015). The change of physical values in a model can be observed by tuning the parameters of the model. Once the model is constructed, parameters for the model have to be identified either by direct measuring, calculation, or approximation. Given measurements from the machine, parameters are tuned until simulations closely mimic the actual measurements. By performing consistency checks of the process against a model of the process, a set of nominal and significant residual parameter values that describe a healthy fault-free system and a faulty system are produced respectively. Hence, the system can detect a set of changed parameters that describe faults. A well-developed Model-based diagnostic can provide: early detection of small faults, more precise fault isolation, fault detection in closed loop systems and process supervision in transient states (Sharma, Dewan and Chatterji, 2015).

Figure 1 shows the typical structure of Model-based diagnostic system, which consists of residual generation and residual calculation.

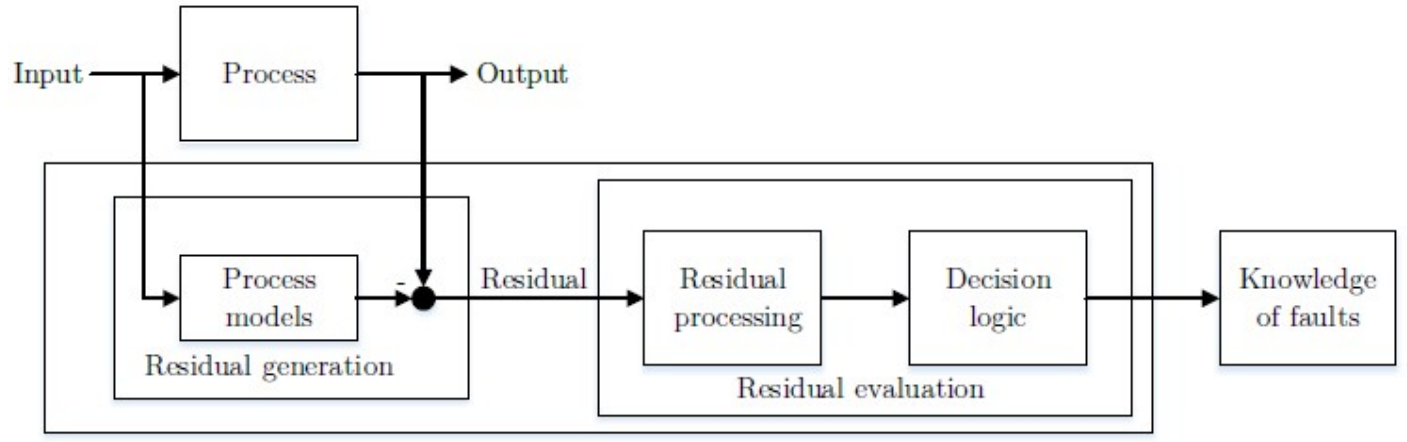

Figure 1: General structure of model-based diagnosis (Sharma, Dewan and Chatterji, 2015)

Rahul and Gupta (2014), examined the FD in rotating of turbine shaft by analyzing its vibration signals using Fast Fourier Transform (FFT) technique. The study also presented an updated review of a variety of vibration feature extraction techniques that have demonstrated success when applied to rotating machinery. By using this tool, the vibration signals were decomposed in order to extract the transient information from the signals. In conclusion, the authors stated that both the time and frequency domain information should be used in conjunction for effective and correct diagnosis of faults in machines. The study observed the rise of amplitude at the pertinent frequencies for turbine set in Fourier transform to interpret the fault in an adequate manner. In order to understand the dynamic characteristics of machinery faults, Algule and Hujare (2015), developed a model of complete motor flexible coupling rotor system capable of describing rotor unbalance and shaft misalignment. The authors observed that, imbalance is the most common cause of machine vibration, as an unbalanced rotor always causes more vibration and generates excessive force in the bearing area and reduces the life of the machine. Experimental studies were performed on a rotor to predict the unbalance in rotor. The vibrations were measured at different speeds using FFT and the results showed that as the speed increased the amplitude also increased. Nembhard et al.(2014) developed a simplified fault diagnosis method that used just a single vibration and a single temperature sensor on each bearing. The study attempted to overcome the complexity of traditional practice in vibration-based condition monitoring $(\mathrm{CM})$ of rotating machines with a multiple bearing system, such as turbo-generator sets. The authors introduced an experimental method where both temperature and vibration signals were combined for CM by developing a diagnostic technique that used fewer sensors. The authors claimed that an opportunity existed to integrate temperature and vibration data for effective fault detection (FD). Temperature measurements were used to compensate for the reduction in vibration sensors while replacing the need for advanced and complex signal processing of the vibration data. A model-based approach was described 
by Loparo, Falah and Adams (2003), for the detection and diagnosis of faults and undesirable operating conditions in rotating machinery. The method was based on a nonlinear filtering approach to FD where Modelbased observers were designed for each fault mode of interest, and their outputs were combined in a nonlinear post processor. The rotor response and orbits at the journal bearing were determined both experimentally and computationally. Jalan (2013), acknowledged that Vibration in rotating machinery was a major concern for modern industries where unbalance and shaft crack in rotor bearing system were the common and principal source of vibration. The research further stated that the presence of these faults changed the dynamic behavior of the system. These changes were taken into account by equivalent loads acting on the healthy system model. Equivalent loads on the system generated a dynamic behavior identical to that of the real faulty system. Hence the study designed a Model based technique for fault diagnosis of rotor-bearing system which was used to detect and distinguish the presence of unbalance and crack in the system. By applying the proposed Model-based technique, the research showed that faults, i.e., unbalance and crack of rotor-bearing system could easily be distinguished which is not possible by the use of simple Fast Fourier Transforms (FFT) analysis only.

The literature review indicates that simple frequency response analysis has mainly been applied to detect rotor bearing system fault. Very little attempt has been made to apply a Model-based FDI system in which not only the type, but also the severity and the location of the fault can be identified. Difficulty is encountered in distinguish between misalignment and crack faults when simple frequency response analysis is used alone, as both types of faults yield a similar frequency response (Zhao et al., 2019). In this study, a model- based technique for fault diagnosis of a turbocharger rotor system will be developed to detect and distinguish the presence of imbalance in the system which is not possible by simple frequency response analysis only.

Most of the researchers have concentrated on experimental models that have not been modelled with reference to a specific industrial turbomachinery. In order to extend the findings of this work to other existing turbochargers and similar turbomachinery, this research will demonstrate the use of an imbalance fault model by applying it to an identified turbocharger unit whose configuration can be geometrically, kinematically and dynamically compared with turbochargers currently being used in the industry. Lastly, the area involving rotations of shaft with variable cross sections has not been sufficiently explored, and the literature review indicates that studies perform experiments using ball bearings. It is of interest to know how other types of bearings would respond to such fault simulations. Therefore, this study focused on identifying imbalances faults induced in a typical turbocharger shaft of variable cross section and supported on hydrodynamic floating rings bearings (FRB).

\section{Methods and materials}

\subsubsection{Healthy TC rotor model formulation}

According to Mayes and Penny (1998), the vibrations represented by the displacement vector $\vec{r}_{0}(t)$ at $N$ degrees of freedom (DOF) of the undamaged TC rotor system due to the operating load $F_{0}(t)$ during normal operation, can be described by a linear equation of motion as:

$$
[M]_{N \times N}\left\{\vec{r}_{0}^{*}(t)\right\}_{N \times 1}+[B]_{N \times N}\left\{\vec{r}_{0}(t)\right\}_{N \times 1}+[K]_{N \times N}\left\{\vec{v}_{0}(t)\right\}_{N \times 1}=\left\{F_{0}(t)\right\}_{N \times 1}
$$

where; $[M]$ is a $N \times N$ mass matrix

$[B]$ is a $N \times N$ damping matrix

$[K]$ is a $N \times N$ stiffness matrix

The vibrations, are represented by the vector $\left\{\vec{r}_{0}(t)\right\}$ at $N$ degrees of freedom of the healthy rotor system, owing to the operating load $\{F(t)\}$ during normal operation. These matrices take into account the effect of bearings, and gyroscopic effects.

\subsubsection{Faulty TC rotor model formulation}

The dynamic behavior of the TC fluctuates due to the occurrence of a fault in the rotor system. The degree of the change depends on the fault parameter $\beta$, which describes the type, location, and magnitude of the fault. The fault-induced change in the vibrational behavior was characterized by the additional loads acting on the healthy system. The equation of motion becomes (Mayes and Penny, 1998):

$$
\lfloor M\rfloor\{\ddot{r}(t)\}+\lfloor E\rfloor\{\dot{r}(t)\}+\lfloor K\rfloor\{r(t)\}=\{F(t)\}+\{\Delta F(\beta, t)\rfloor
$$

Subtracting the equation of motion for the healthy system, Equation 1, from that of faulty system, Equation 2 , the equation of motion for residual vibration is represented as:

$$
[M]\{\Delta \vec{r}(t)\}|\{B]\{\Delta \vec{r}(t)\}|\lfloor K]\{\Delta \vec{r}(t)\}=\{\Delta F(\beta, t)\}
$$


Where the residual displacements $\{\vec{r}(t)\}$, velocities $\left\{\Delta \overrightarrow{\vec{r}^{*}}(t)\right\}$, and accelerations $\{\Delta \overrightarrow{\vec{r}}(t)\}$ were given by:

$$
\begin{aligned}
& \{\Delta \vec{r}(t)\}_{N \times 1}=\{\vec{r}(t)\}_{N \times 1}-\left\{\vec{r}_{0}(t)\right\}_{N \times 1} \\
& \{\Delta \vec{r}(t)\}_{N \times 1}=\{\vec{r}(t)\}_{N \times 1}-\left\{\vec{r}_{0}(t)\right\}_{N \times 1} \\
& \{\Delta \vec{r}(t)\}_{N \times 1}=\{\vec{r}(t)\}_{N \times 1}-\left\{\vec{r}_{0}(t)\right\}_{N \times 1}
\end{aligned}
$$

\subsubsection{TC rotor Measured vibration response modeling}

Following Modal expansion (see section 2.2), the full residual vibrations response was represented by the difference between the measured normal vibrations $\left\{\vec{r}_{0},(t)\right\}$ of healthy TC system from the measured vibrations $\left\{\vec{r}_{m}(t)\right\}$ of the faulty TC rotor system. Hence, the residual displacements, velocities and accelerations were given by:

$$
\begin{aligned}
& \left\{\Delta \vec{r}_{m}(t)\right\}_{N \times 1}=\left\{\vec{r}_{m}(t)\right\}_{N \times 1}-\left\{\vec{r}_{0}(t)\right\}_{N \times 1} \\
& \left\{\Delta \vec{r}_{m}(t)\right\}_{N \times 1}=\left\{\vec{r}_{m}(t)\right\}_{N \times 1}-\left\{\vec{r}_{o n}(t)\right\}_{N \times 1} \\
& \left\{\Delta \vec{r}_{m}(t)\right\}_{N \times 1}=\left\{\vec{r}_{m}(t)\right\}_{N \times 1}-\left\{\vec{r}_{o m}(t)\right\}_{N \times 1}
\end{aligned}
$$

Finally, the equivalent forces $\{\Delta F(t)\}$ characterizing the unknown faults were calculated by substituting the residual displacements, residual velocities and residual accelerations of the full vibrational state into:

$$
[M]\left\{\Delta \vec{r}_{m}^{*}(t)\right\}+[B]\left\{\Delta \vec{r}_{m}^{\vec{m}}(t)\right\}+[K]\left\{\Delta \vec{r}_{m}^{*}(t)\right\}=\{\Delta F(t)\}
$$

\subsection{Model fitting}

The 'goodness of fit' between the results from the theoretical fault models (mathematical model) and measured equivalent loads from Equation 6 was carried out to fully identify the fault parameter. If there is no noise and no errors due to shape expansion, the experimental residual nodal forces $(\Delta F(t))$ from the measured data would fit exactly that of the mathematical fault model $(\Delta F(3, t))$. To resolve the associated error, and evaluate the strength of association, an approach applying the determination coefficient ' $R^{2}$ ', (Devore, 2012), was used to indicate the 'goodness-of-fit' between the two data sets, expressed as:

$$
R^{2}=\frac{\sum_{i=1}^{n}\left(\Delta F_{\exp i}-\Delta F_{i \text { mod }}\right)^{2}}{\sum_{i=1}^{n}\left(\Delta F_{\exp }-\Delta F_{i x p}\right)^{2}}
$$

The flow chart summarizing the algorithm of the Model based fault identification scheme used in this work is shown in Figure 2.

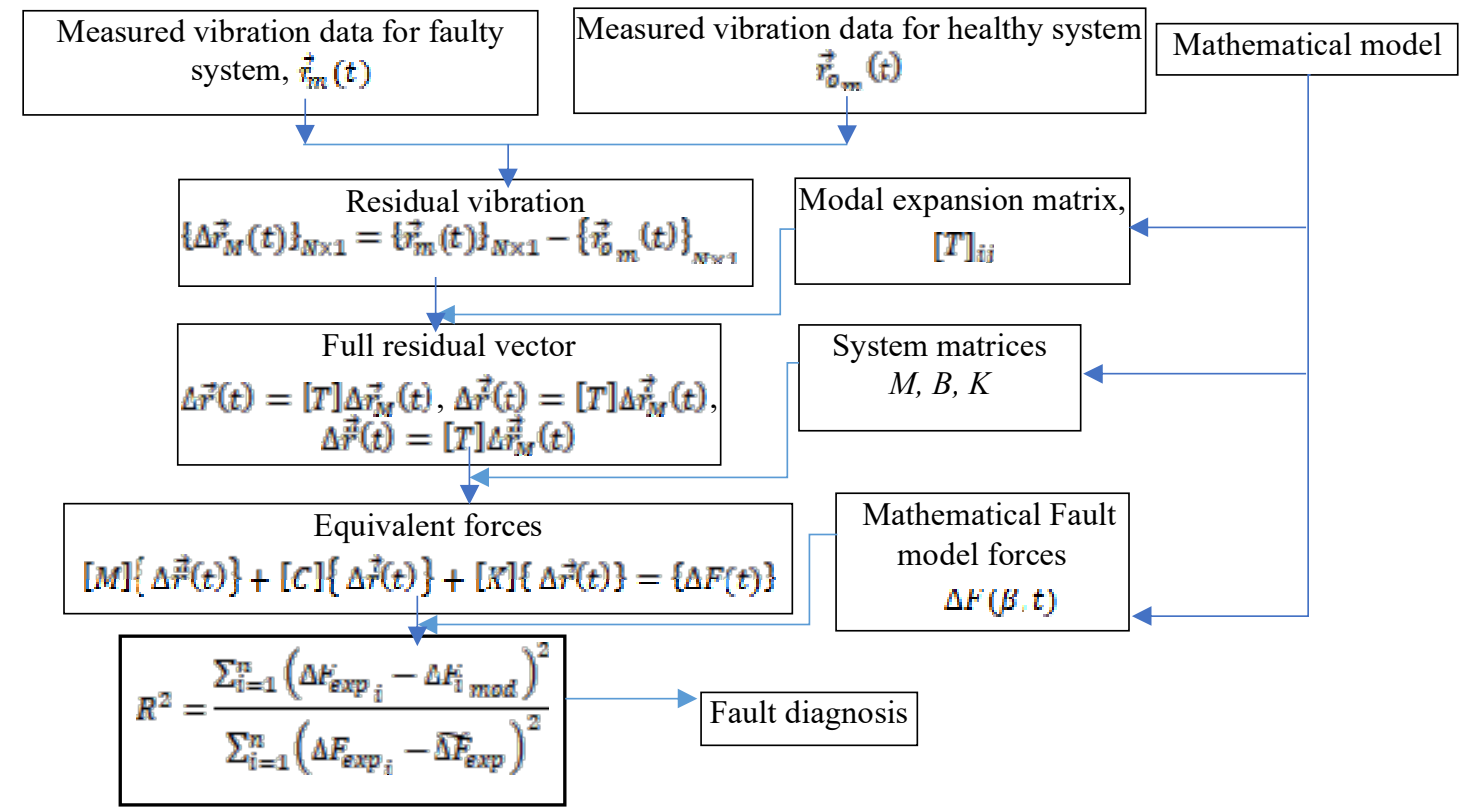


Figure 2: Scheme of model-based fault diagnosis

\subsection{FE modeling of the TC rotor-bearing-disc system}

A TC rotor system consists of turbine and compressor impellers linked by a shared shaft supported by a pair of oil film bearings. Using the FEM approach, the rotor system used in this study, was assembled using elements which included: discs, the shaft segments and the bearings along the axial direction. Unit analysis approach (Ruhl and Booker, 1972), was the used to establish the relationship between the nodal force and nodal displacement.

The rotor was discretized into twelve beam elements which consist of 13 nodes, where node 6 and 9 were bearing locations for two oil film floating ring bearings (FRB). The physical model is shown in Figure 3 (a) and the discretized model of the TC rotor system FE model is illustrated in Figure 3 (b). Lagrangian interpolation functions were then used to approximate the displacement fields of the shaft. The governing equations of the motion are expressed in Equations 1, 2, and 0.

The rotor system motion equation was formed by assembling the global matrices of all the elements. As a consequence, it was possible to transform a continuous rotor system into a system with multiple degrees of freedom. The critical speeds and force response of the system were then obtained by solving a group of linear simultaneous equations. As far as the turbocharger rotor system is concerned, the primary exciting forces for the system vibration include the static and dynamic loads. Static loads denote the lubricant feed pressure acting on the ring, and the dead weight. Dynamic loads include the forces with varied values, such as rotor imbalance, and the bearing hydrodynamic fluid forces.

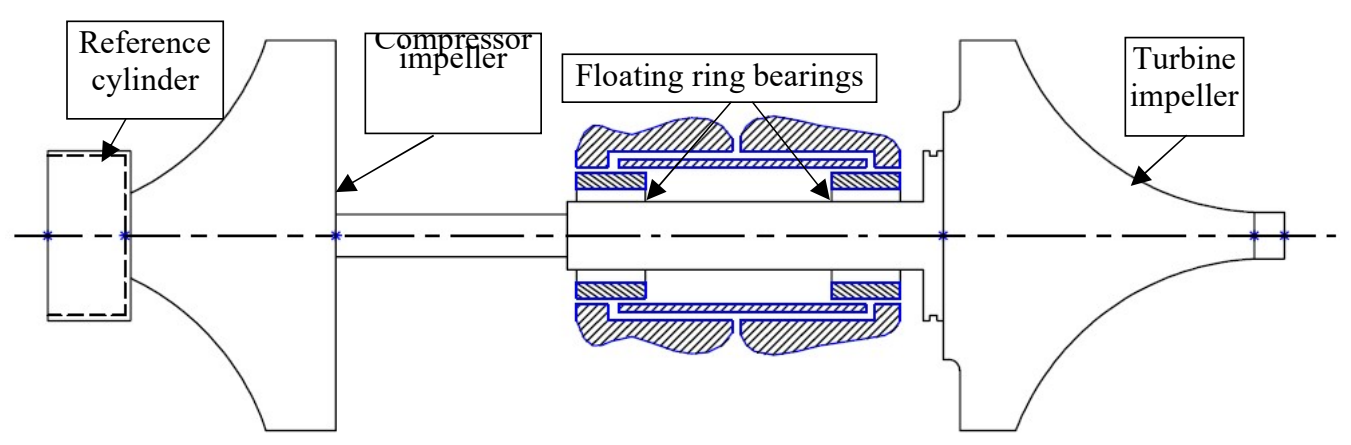

(a)

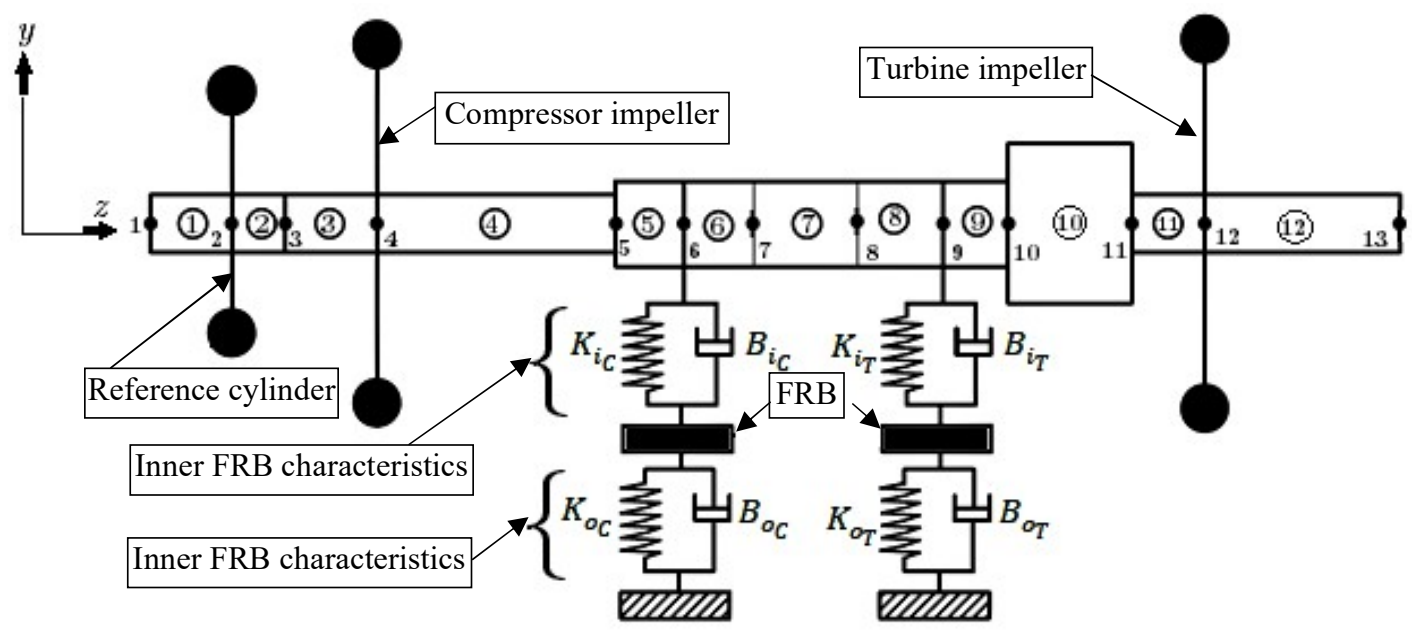

(b)

Figure 3: Turbocharger shaft models: (a) physical model (b) FEM model. 


\subsection{Mode Expansion}

To compute the equivalent loads from the mathematical model of the rotor system, there was need to measure residual vibrations at all degrees of freedom of the model. But practically, it was not possible to install vibration sensors at all node locations, hence, the number of measurement locations was much smaller than the number of model's degrees of freedom. To resolve this problem, the residual vibrations of the non-measurable degrees of freedom was estimated from the measured residual vibrations using the modified System Equivalent Reduction Expansion Process (SEREP) approach (Das and Dutt, 2008), which is a Modal expansion technique, used to reconstruct the measured residual vibrations for rotor-shaft systems. The SEREP expansion technique utilizes the SEREP transformation matrix ' $T$ ' to expand the measured degrees of freedom in all the degrees of the system. According to this approach, the full displacement matrix vector $x_{n}$ is partitioned in to measured ' $a$ ' and nonmeasured ' $s$ ' displacements, and is related to the measured displacement $x_{Q}$ by:

$$
x_{\mathrm{n}}=\left[\begin{array}{l}
x_{a} \\
x_{g}
\end{array}\right]=T x_{a} ; n=a+s
$$

Where, ' $n$ ' is the total DOF of the system, and $T$ the modified SEREP transformation matrix given by:

$$
[\bar{T}]_{2 \mathrm{nxa}}=\left[\bar{\psi}_{R}\right]_{2 \mathrm{nxm}}\left[\bar{\psi}_{L_{1}}\right]_{\text {mxa }}^{T}\left[\left[\bar{\psi}_{L_{1}}\right]^{T}\right]_{[\times m}^{+}\left[\bar{\psi}_{R_{1}}\right]_{a \times m}^{+}
$$

Where: $\left[\bar{\psi}_{2_{1}}\right]$ is the partitioned truncated analytical modal matrix of left eigen vectors, and $\left[\bar{\psi}_{k}\right]_{2 n \times m}$ is the truncated analytical modal matrix of right eigen vectors partitioned into measured ' $a$ ' and slave ' $s$ ' coordinates so that:

$$
\left[\bar{\psi}_{R}\right]_{\operatorname{sn} m}=\left[\begin{array}{l}
{\left[\bar{\psi}_{R_{1}}\right]_{2 \mathrm{~mm}}} \\
{\left[\bar{\psi}_{R_{2}}\right]_{g \mathrm{sm}}}
\end{array}\right]
$$

$m$ is number of retained modes and is equal to the number of independently measured DOFs. i.e., $(m=a)$. the superscript ' + ' signifies the Moore-Penrose pseudo-inverse of the operand matrix.

\subsection{Faults Models}

For the proposed Model-based fault identification method, each fault was represented by a mathematical model describing the relation between the fault parameters $\beta$ and the equivalent force $\Delta F(\beta, t)$. In this way, the mathematical representation of equivalent loads was referred to as a Fault Model (Jalan, 2013). A detailed discussion is given in the following sections.

\subsubsection{Disc Imbalance fault model}

In this work, for illustrating the relation between fault parameters and the corresponding equivalent load, a single imbalance $u_{n}$ with the phase angle $\delta_{n}$ acting on the rotor at position node number $n$ was considered as shown in Figure 4.

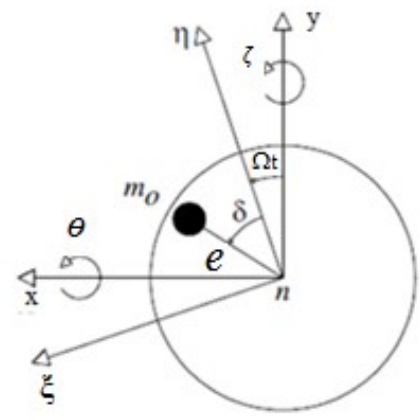

Figure 4: Node $\mathrm{n}$ of the rotor disk with imbalance

Defining the vector $\vec{\xi}_{n}$ of generalized displacements of the node $n$ as:

$$
\vec{\xi}_{n}=\left\lceil x_{n}, y_{n}, \theta_{n}, \zeta_{n}\right\rceil^{T}
$$

A single imbalance fault acting on the rotor at position $n$ was replaced by the equivalent forces: 


$$
\begin{aligned}
\Delta F_{n h}(\beta, t) & =\Omega^{2} u_{n} \sin \left(\Omega t+\delta_{n}\right) \\
\Delta F_{n v}(\beta, t) & =\Omega^{2} u_{n} \cos \left(\Omega t+\delta_{n}\right)
\end{aligned}
$$

where: $\Delta F_{\text {sh }}(\beta, t)=$ equivalent forces in the horizontal at node $n$

$$
\Delta F_{n V}(\beta, t)=\text { equivalent forces in the vertical at node } n
$$

The equivalent forces on all other nodes are zero. Hence, the fault parameters of the single imbalance were given by:

$$
\beta_{\text {unb }}=\left[n, u_{n}, \delta_{n}\right]^{T}
$$

From Figure 4, the imbalance forces acting at node ' $n$ ' are modeled as:

$$
\left[\begin{array}{l}
F_{u b X} \\
F_{u b Y}
\end{array}\right]=m_{u b} e_{u} \Omega^{2}\left[\begin{array}{l}
\cos \left(\Omega t+\delta_{n}\right) \\
\sin \left(\Omega t+\delta_{n}\right)
\end{array}\right]
$$

Applying trigonometric equalities, Equation 14 can be written as:

$$
\left[\begin{array}{l}
F_{\text {sh }} \\
F_{u b r}
\end{array}\right]=m_{u b} e_{u} \Omega^{2}\left[\begin{array}{cc}
-\sin \delta_{n} & \cos \delta_{n} \\
\cos \delta_{n} & \sin \delta_{n}
\end{array}\right]\left[\begin{array}{c}
\sin (\Omega t) \\
\cos (\Omega t)
\end{array}\right]
$$

These matrices, were added to node number 2 in the global force matrix during FE imbalance fault model analysis. A MATLAB code was then developed to integrate the matrix in Equation 15 to the affected node in the FEM global force matrix during TC rotor imbalance fault model analysis. After assembling the different shaft beam elements, the rigid discs and the discrete hydrodynamic FRB stiffness, the equation of motion of the complete faulty rotor system in a fixed co-ordinate system was written as:

$$
M[\ddot{r}(t)]+B[\dot{r}(t)]+(F)[r(t)]=Q+W
$$

where:

$M$ is the mass matrix which includes mass matrices of the shaft and rigid discs.

$B$ is the matrix for the shaft internal damping, the damping of the bearing supports and the gyroscopic moments.

$K$ is the global stiffness matrix of the TC shaft and bearing supports.

$Q$ and $W$ is the vector of gravity and imbalance forces due to the disks and the shaft, respectively.

From Equation 16, an additional MATLAB code was implemented to solve its Eigen value problem and TC shaft response due to imbalance faults on the TC rotor at selected rotational speeds.

\section{Experimental apparatus}

In order to validate the theoretical fault models, experimental data was required. Hence, a TC test rig was developed with the aim of investigating the turbocharger shaft response under healthy and faulty conditions.

\subsection{Test rig design}

To ensure successful TC Test-rig performance, this study implemented a primary design criterion that took in to consideration a TC test rig that was comprised of a TC unit assembled together with other subsystems: compressed air supply system, data acquisition (DAQ) system, lubrication system, and a regulated power supply system. The developed TC test rig system pipping schematic layout is shown in Figure 5.

Vibration sensors and rotational speed sensors were installed for measurement of TC dynamic characteristics. These sensors included: high precision non-contact, linear, analog displacement eddy current proximity transducers to measure shaft bi-axil vibrations relative to the bearing housing, and a digital color-mark photoelectric sensor to monitored the TC shaft rotational speed as shown in Figure 6.

The graphic programming language LabVIEW 2014 professional version was implemented to process signals from the DAQ system. Arduino Integrated development Environment (IDE) software program was used to collect and interface sensor signals from the Data acquisition card with the LabVIEW software program environment. The experimental set-up is shown in Figure 7. 


\subsubsection{Fault simulation}

for imbalance fault simulation, imbalance was induced by fixing masses in one of two equally spaced holes machined in the reference-cylinder as shown in Figure $6 \mathrm{~b}$. Each hole is of $3 \mathrm{~mm}$ diameter and at an eccentric radius of $10 \mathrm{~mm}$ from the TC rotor axis.

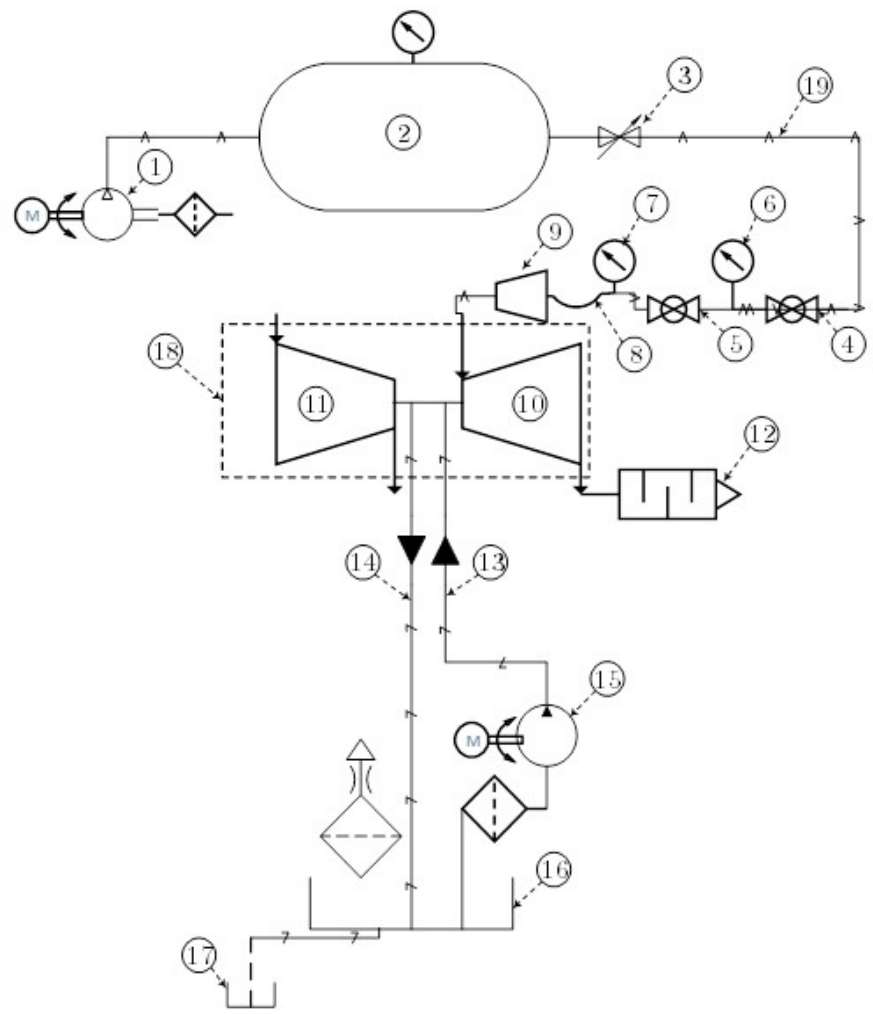

1. Air compressor 2. Air reservoir 3. Main shut-off valve 4. Ball valve (V1) 5. Ball valve (V2) 6. Supply pressure gauge 7. Test pressure gauge 8. Flexible connection 10. TC Turbine impeller 11. TC Compressor impeller 12. Exhaust silencer 13. Lube oil supply 14. Lube oil return 15. Lube oil pump 16. Lube oil tank 17. Lube oil drain 18. Turbocharger unit 19. Compressed air supply main.

Figure 5: Developed TC test rig system pipping schematic layout.
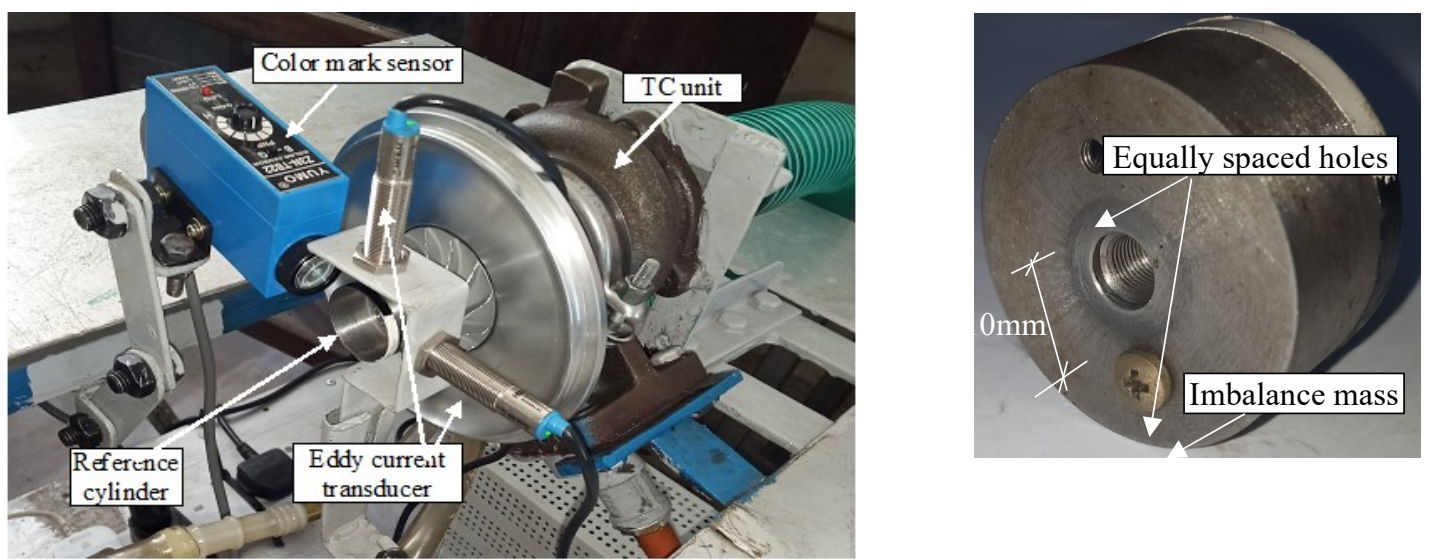

(a)

(b)

Figure 6: (a) Sensor assembly (b) reference-cylinder 


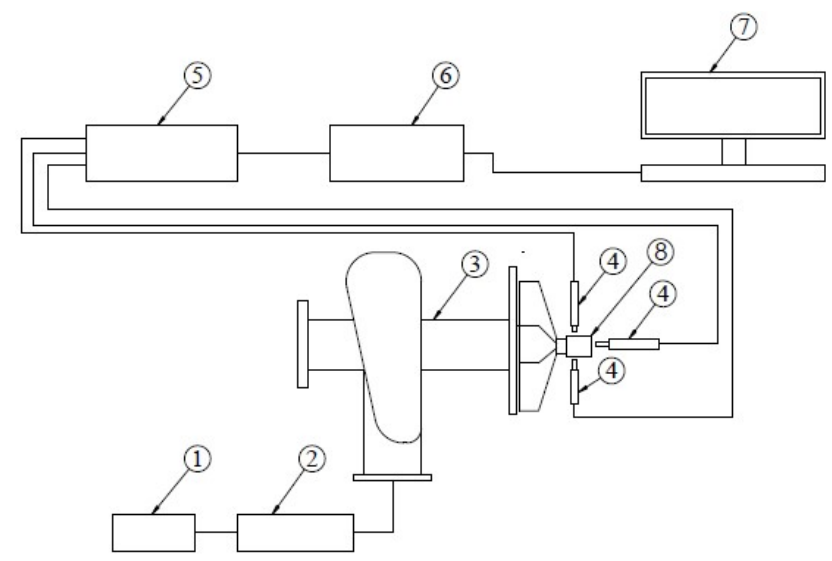

1. Compressed air source 2. Air preparation equipment 3. Turbocharger unit 4. Sensor assembly 5 . Digital to Analogue converter (DAC) 6. DAQ 7. Laptop. 8. Reference cylinder

Figure 7: TC test-rig experimental set-up.

\section{Results and discussion}

\subsection{TC rotor Fault model validation.}

To identify faults, fault Models were developed using the FEM approach. For credible results, FEM models developed for imbalance faults were first validated by making comparisons between the response behaviors of the theoretical FEM models and experimental data obtained with respect to their Amplitude, Time and Frequency response.

\subsubsection{Imbalance Fault: Amplitude, Time and Frequency response.}

Figure 8, shows the Time response measurement data of the eddy current shaft displacement sensors during runup. The sensors data represent the lateral displacement at node 2 located at the reference -cylinder (see Figure 6) on the TC rotor compressor side. The data shows the results of tests carried out for 52 seconds with imbalance masses of 0.6 and $0.3 \times 10^{-3} \mathrm{~kg}$ hereafter in this study referred to as $m_{1}$ and $m_{2}$ respectively.

Figure 8 (a) shows the run-up test with imbalance mass $m_{1}$, It was observed that: Up to $t \approx 23.4$ s the rotor was stable and performed imbalance vibrations around a stable equilibrium position. The rotor eccentricity showed high peaks near $4.475 \mathrm{~s}$ (at rotor speed of $\approx 25 \mathrm{krpm}$ ), this was evidence of the existence of the rotor synchronous component as the rotor passed its first bending critical frequency, Schweizer (2010), reported similar results. When rotor speed increased to $56 \mathrm{krpm}(t \approx 23.4 \mathrm{~s})$, instability commenced to occurs in the inner oil film and the rotor became completely unstable. From the results, it is clear that FRB eccentricity was approaching unity. When TC rotor speed was increased even further, the FRB eccentricity remained large and was characterized by a whip lock at resonance as indicated. This finding was in-line with previous studies (Eling, 2018).

Figure 8 (b) shows the run-up test with imbalance mass $m_{2}$, It was observed that: Up to $t \approx 23.4 \mathrm{~s}$, the rotor was stable and performed imbalance vibrations around a stable equilibrium position. the rotor eccentricity showed high peaks $\approx 0.04 \mathrm{~mm}$ near $4.475 \mathrm{~s}$ (at rotor speed of $\approx 25 \mathrm{krpm}$ ), this was evidence of the existence of the rotor synchronous component as the rotor passed it's the first bending critical frequency. When rotor speed was increased to $56 \mathrm{krpm}(t \approx 23.4 \mathrm{~s})$, instability again commenced in the inner oil film and the rotor become completely unstable. From the results, as it was observed previously for imbalance mass $m_{1}$, it was clear that FRB eccentricity was approaching unity. And When rotor speed was increased even further, the FRB eccentricity remained large and was again characterized by a whip-lock at resonance. 


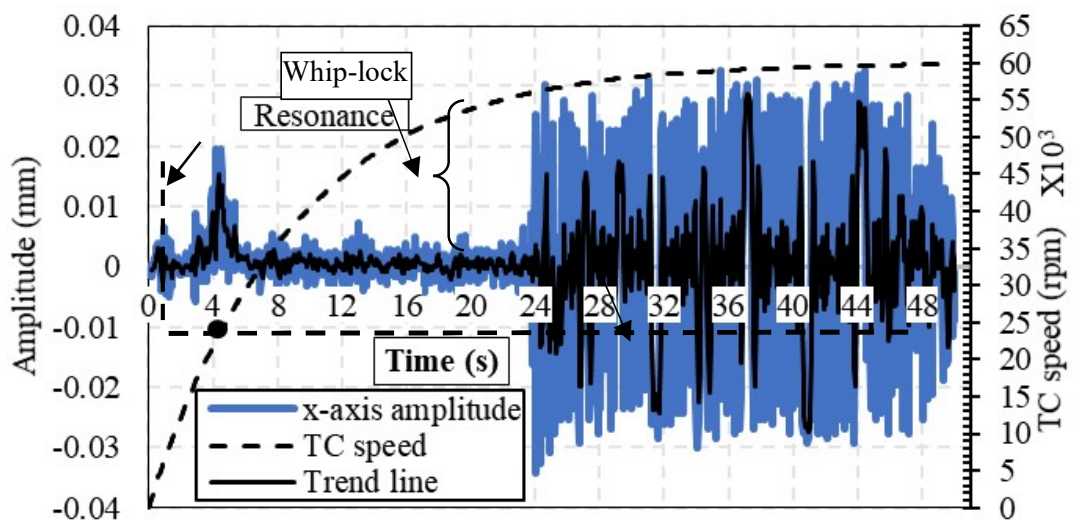

(a)

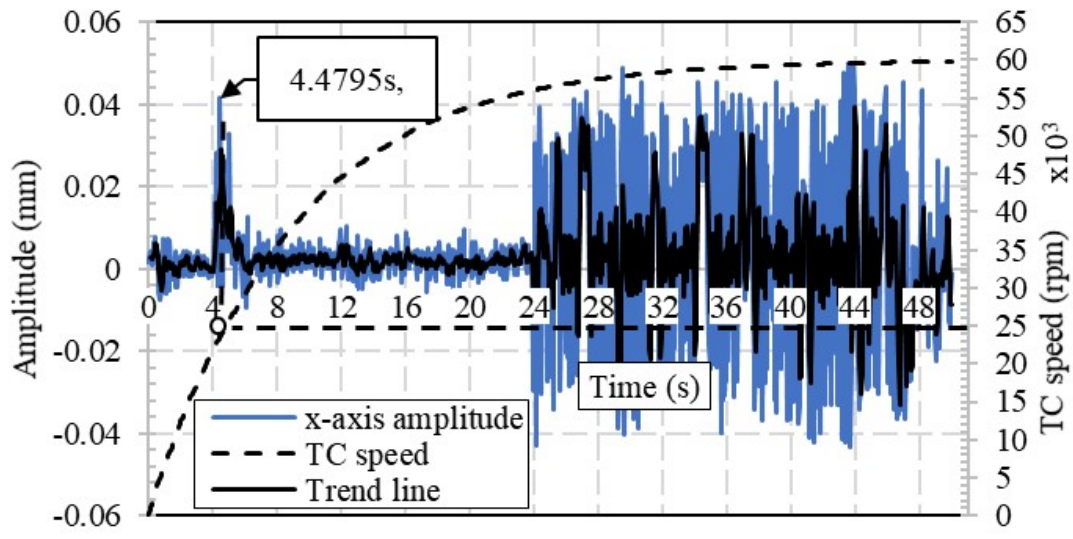

(b)

Figure 8: TC shaft Run-up Time response to induced imbalance fault: (a) $m_{1}$ (b) $m_{2}$.

The run-up results from the Time response data were used to generate FFT plots as shown in Figure 9 (a) for data points within the stable synchronous region as explained in the section above (i.e., first $23.4 \mathrm{~s}$ for imbalance $m_{1}$ and $m_{2}$ respectively). From these results, it is clear that the FFT plots indicated resonant amplitudes at $\approx$ $417 \mathrm{~Hz}$ for both TC rotor imbalance run-ups. Resonant amplitude associated with $m_{2}$ were greater than the ones for $m_{1}$ this was due to the increased centrifugal imbalance forces generated by the former owing to its magnitude. These findings are in agreement with findings reported by Zhang (2012).

As shown in Figure 9 (b), the result of the predicted FRF plots generated from the TC FE imbalance fault mathematical model were in good agreement when compared with The FFT results. the critical speed was correctly predicted and the resonant amplitudes also showed good agreement. Hence, these results confirmed that the developed FEM model for imbalance fault was valid. 


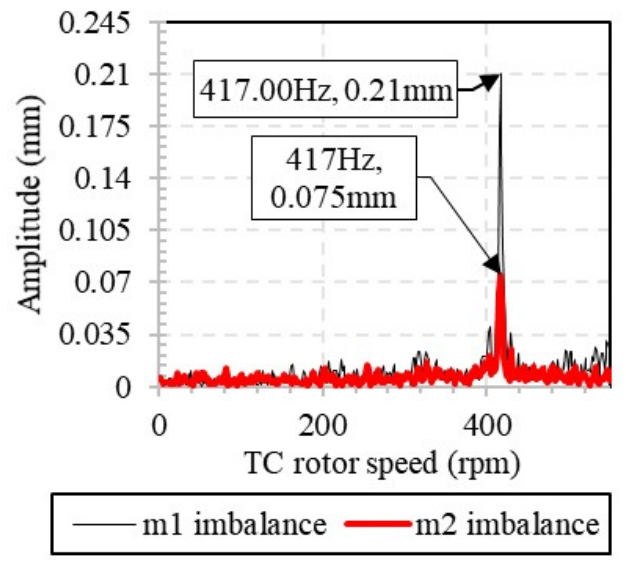

(a)

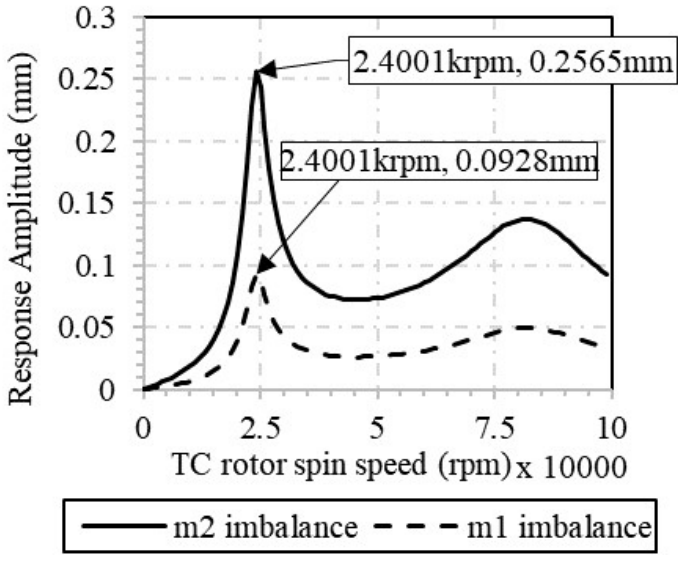

(b)

Figure 9: (a) FFT for induced imbalance fault (b) FE imbalance fault model FRF.

\subsection{Fault identification.}

To identify TC rotor Imbalance faults, amplitude due to fault on the system was extracted from measured Time response data measured at selected constant TC rotor test spin speeds. This data was obtained by sensors positioned at the TC reference-cylinder (see Figure 6). After extraction, this data was then used in the Fault identification scheme explained earlier in section Error! Reference source not found.to generate the residual displacements $\Delta r_{m}$ and residual forces $\Delta F_{m}$ at each node on the TC rotor for fault identification. Figure 10 to Figure 13, shows the measured TC shaft Time response data in X and Y directions measured at TC spin speeds of $7500 \mathrm{rpm}$ and 15000rpm respectively. With a rotor imbalance of $m_{1}$ shown in Figure 10 (a) and (b), it was observed that: the TC shaft performed the periodic motion in X and Y directions. The displacement signals measured had glitches at some places hence, were not smooth. when the rotational speed was increased to 15000rpm as shown in Figure 11 (a) and (b), increase of the amplitude in both directions was observed. In addition, evidence that shaft motion comprised of the synchronous component was evident from the corresponding FFT spectrum diagrams.

Comparable experimental results were observed when rotor imbalance was $m_{2}$ as shown in Figure 12 and Figure 13, except for the increase of the amplitude in both directions which was as a result of the larger rotor imbalance centrifugal forces. Table 1 below summarizes the findings from the measured TC shaft displacements extracted from the measured Time response data. This data was then integrated in the Modal Expansion scheme for further analysis as discussed in the sections that follow.
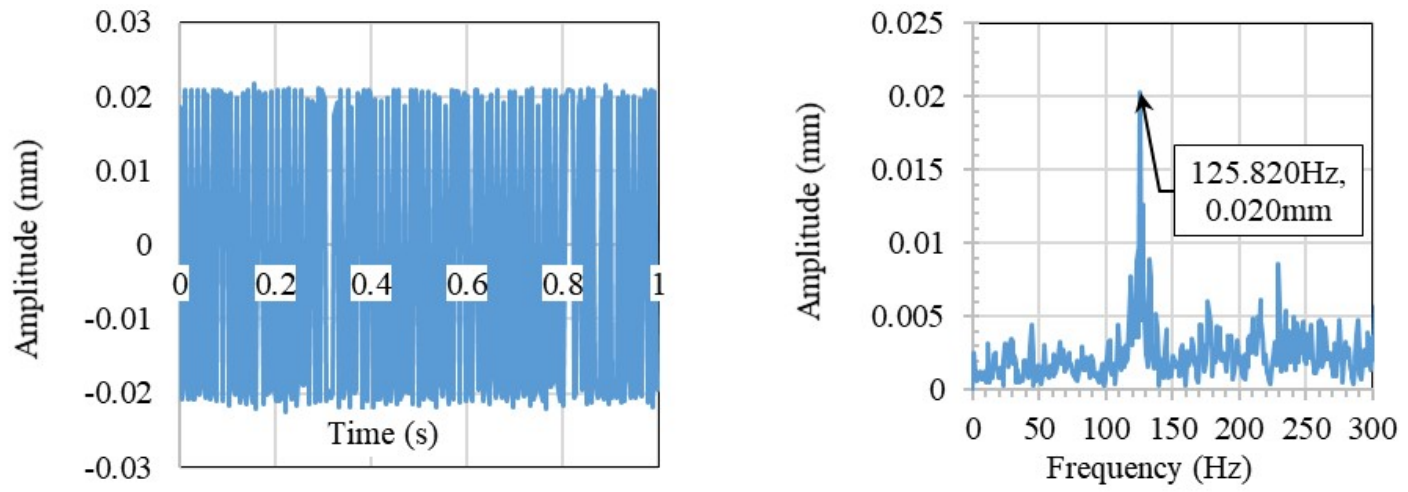

(a) 

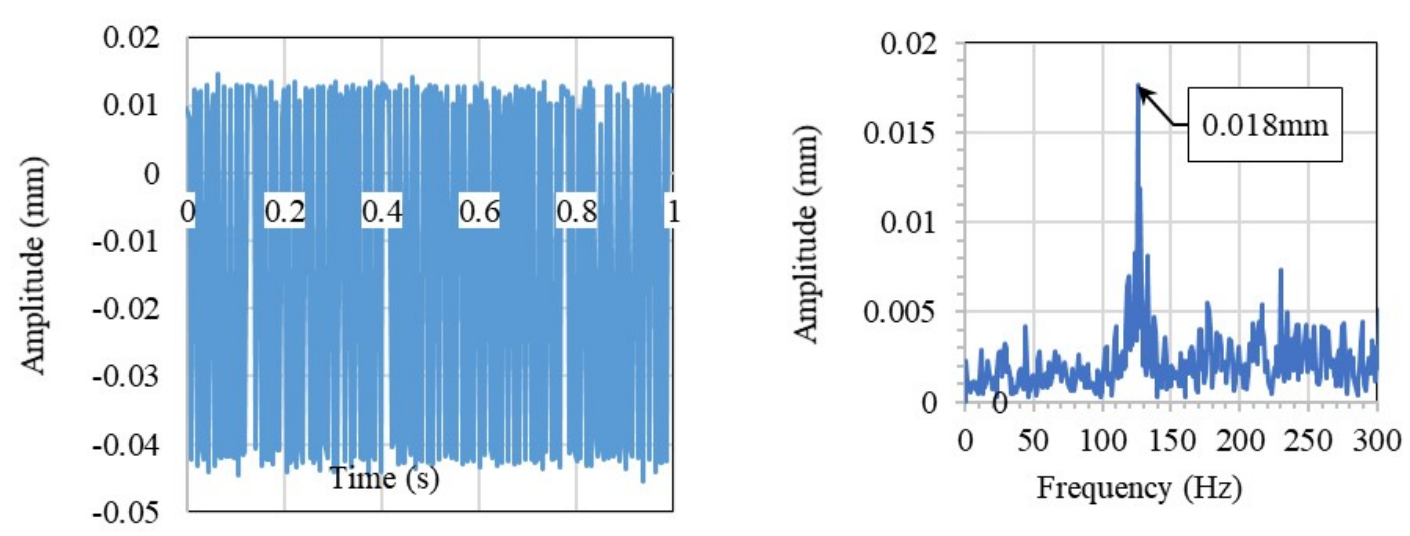

(b)

Figure 10: TC shaft Imbalance $m_{1}$ Time response and FFT plots at 7500rpm: (a) X-axis: (b) Y-axis.
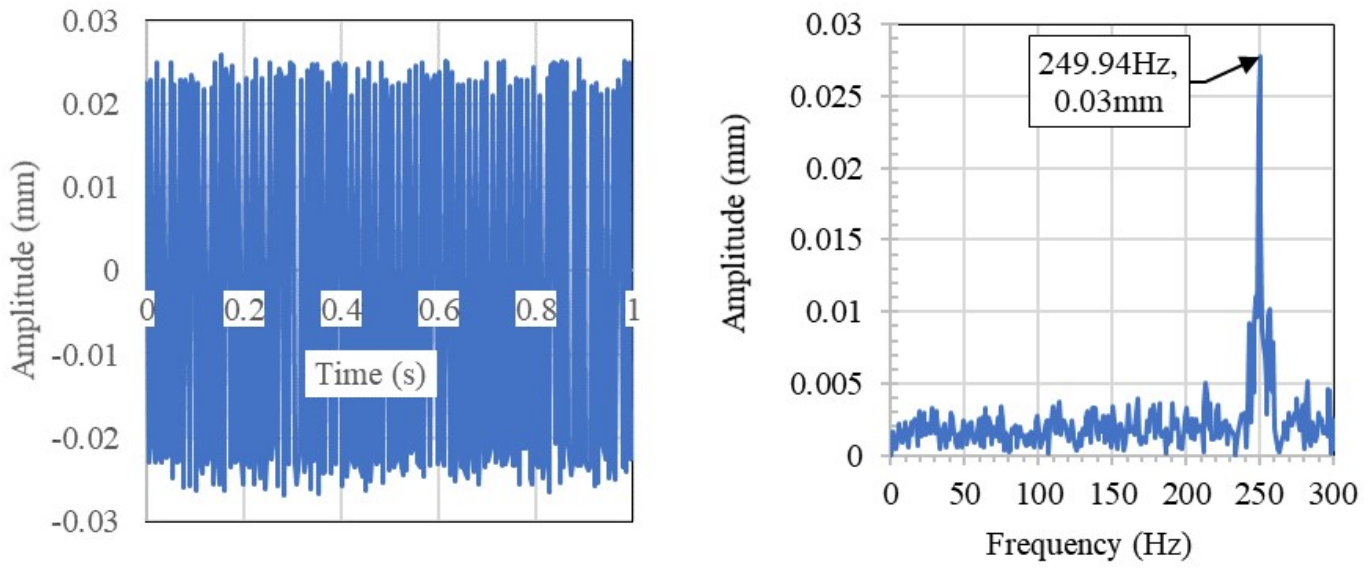

(a)
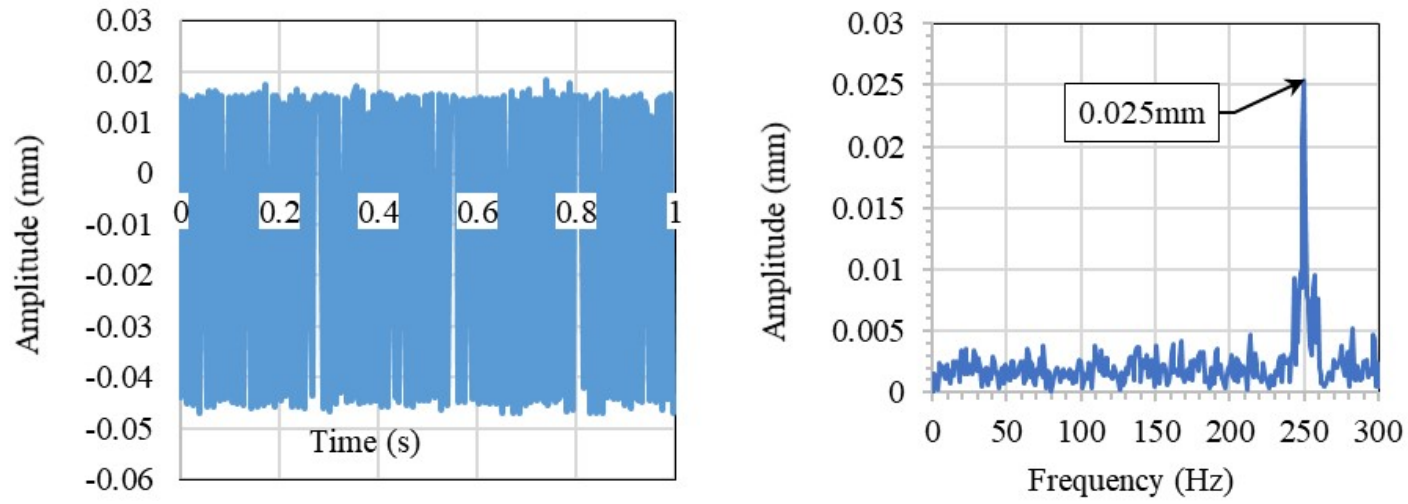

(b)

Figure 11: TC shaft Imbalance $m_{1}$ Time response and FFT plots at 15krpm: (a) X-axis: (b) Y-axis. 


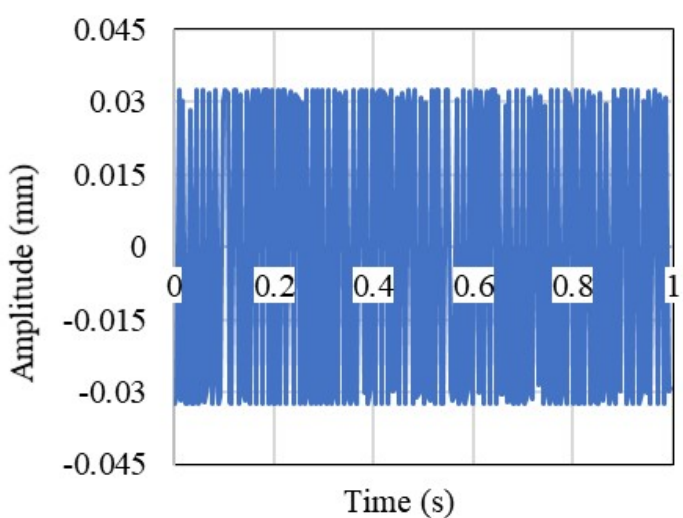

(a)
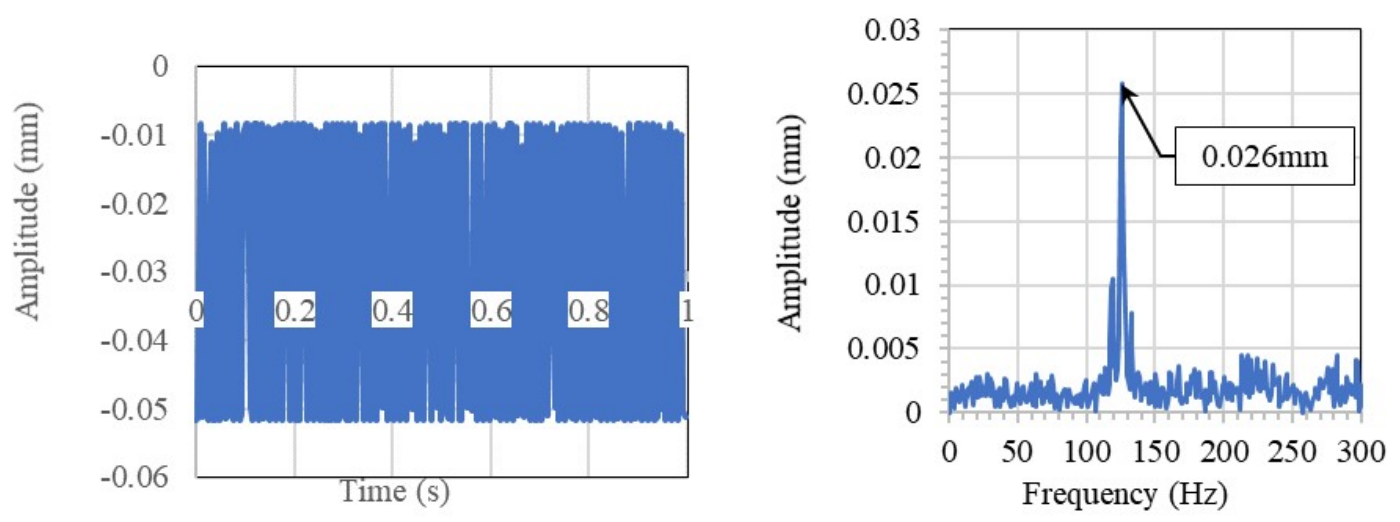

(b)

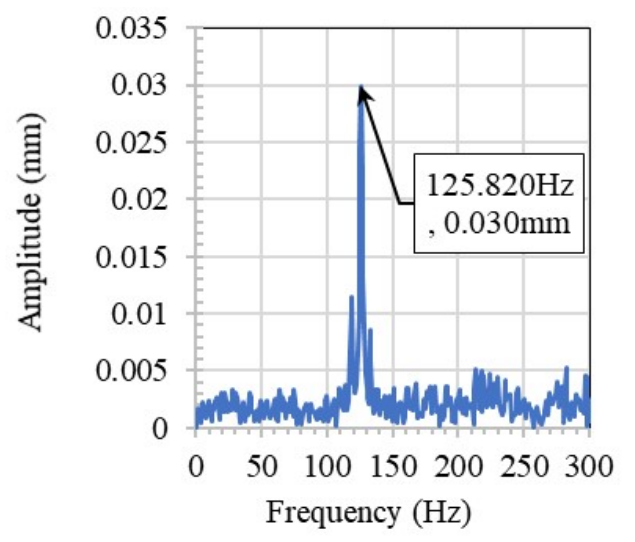

Figure 12: TC shaft Imbalance $m_{2}$ Time response and FFT plots at 7500rpm: (a) X-axis: (b) Y-
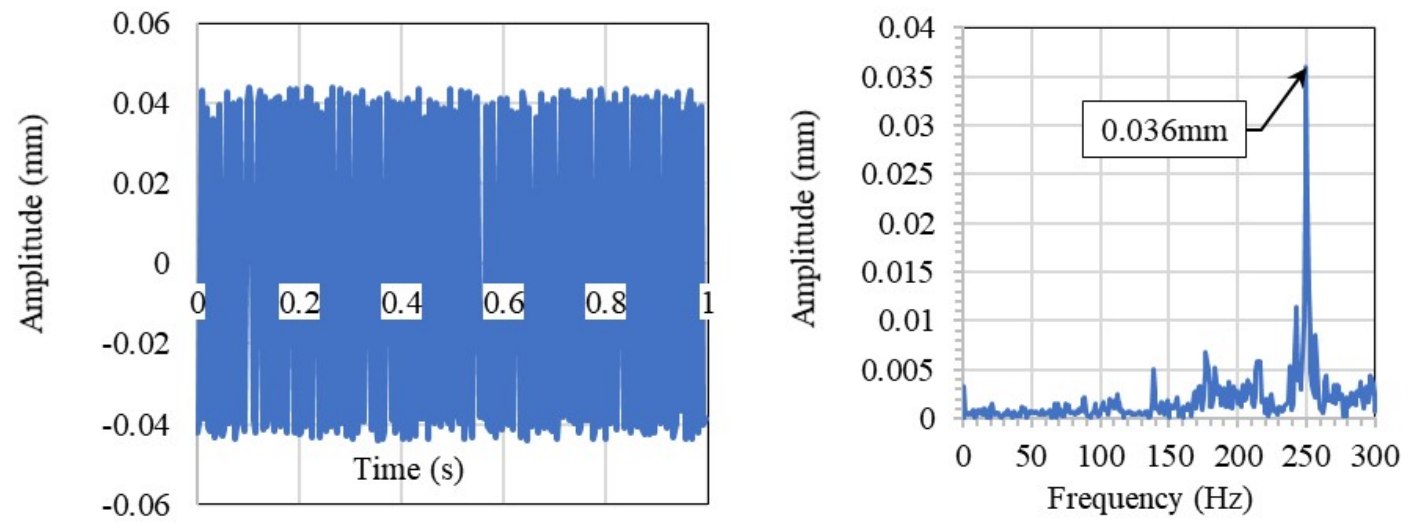

(a) 

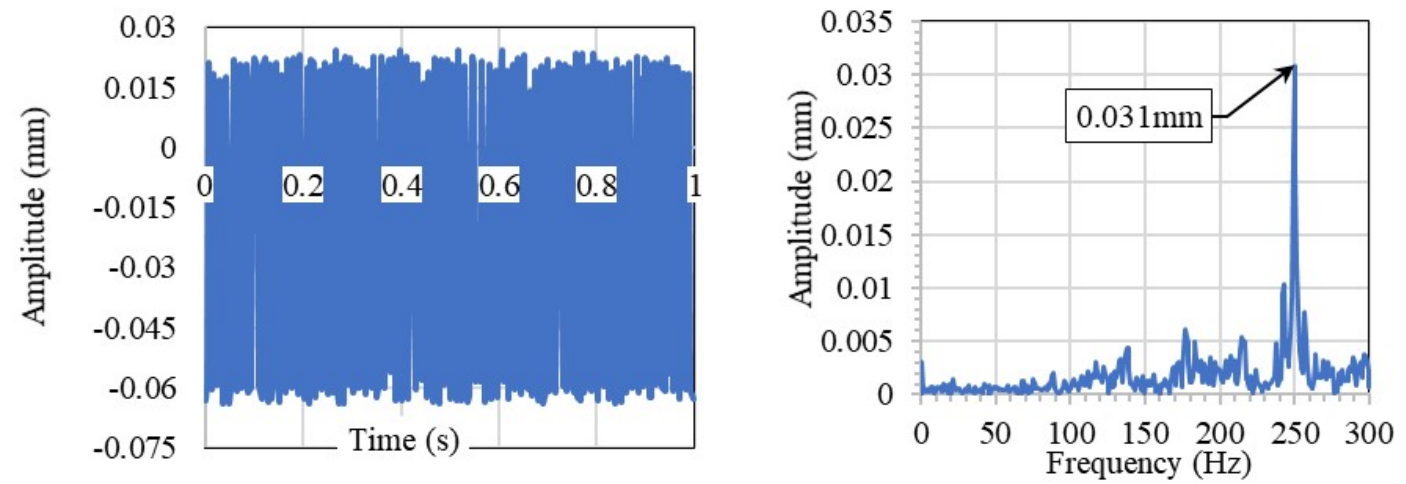

(b)

Figure 13: TC shaft Imbalance $m_{2}$ Time response and FFT plots at 15krpm: (a) X-axis: (b) Y-axis.

Table 1: TC shaft amplitude extracted at node 2 due to imbalance

\begin{tabular}{ccccc}
\hline Test speed (rpm) & \multicolumn{2}{c}{7500} & \multicolumn{2}{c}{15000} \\
\hline Imbalance $(\mathrm{kg})$ & $\mathrm{X}(\mathrm{mm})$ & $\mathrm{Y}(\mathrm{mm})$ & $\mathrm{X}(\mathrm{mm})$ & $\mathrm{Y}(\mathrm{mm})$ \\
\hline$m_{1}$ & 0.020 & 0.018 & 0.03 & 0.025 \\
\hline$m_{2}$ & 0.03 & 0.026 & 0.031 & 0.036 \\
\hline
\end{tabular}

\subsubsection{Imbalance: nodal residual forces.}

Experimental residual forces were calculated from Time Response data discussed in section 4.2 above using Mode expansion scheme discussed in section 2. The experimental residual forces were determined and compared to the numerical residual forces for $6 \times 10^{-6}$ and $3 \times 10^{-6} \mathrm{~kg}-\mathrm{m}$ imbalances respectively. For both numerical and experimental approaches, the residual forces in the horizontal direction (X-axis) for all 13 nodes at specific rotational test speeds, with imbalance fault on the TC shaft system are shown in Figure 14 to Figure 15. From the numerical results, it was clear that very high residual forces were only observed at nodes 2 where the imbalance was situated together with minor picks at the FRB locations i.e., node 6 and 9. On the other hand, the experimental results showed a major pick at node 2. Noise due to shape expansion coupled with the limitation of using a few DOF data points to estimate accurately the full vibration data of unmeasured DOF led to the occurrence of extra minor residual picks at node 4, and 12 respectively. However, these results showed good agreement between the theoretical and experimental results respectively. Hence, Model based fault identification method implemented in this work, was able to effectively identify the magnitude and exact location of the induced imbalance faults in the TC rotor system. With reference to the obtained residual nodal forces, the 'goodness of fit' between the experimental and the predicted theoretical FE model data results was evaluated. Correlation between the two data sets was conducted by calculating their respective coefficient of determination ' $R$ '. Error! Reference source not found., summarizes the findings from the correlation analysis between the experimental and theoretical residual nodal forces data results for the imbalance faults, as referred to the TC test speeds adopted in this study i.e., 7500rpm and $15 \mathrm{kprm}$ respectively. From the results, it is clear that the 'goodness-of-fit' between the model and the experimental data was within acceptable limits. 


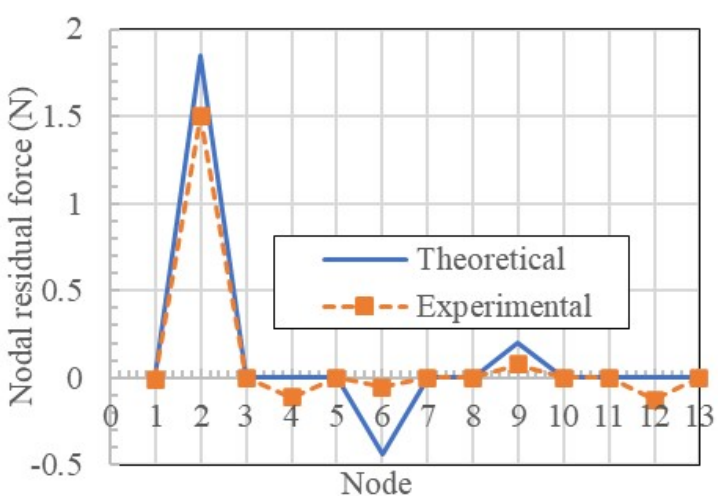

(a)

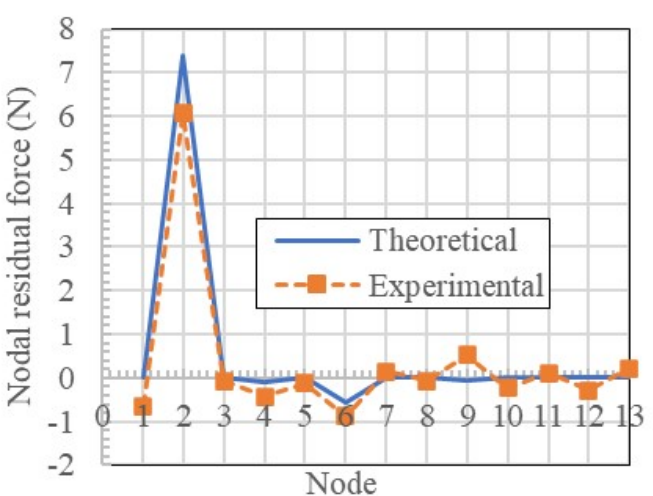

(b)

Figure 14: Residual nodal forces Imbalance $m_{1}$ at: (a) 7500rpm (b) $15 \mathrm{Kprm}$

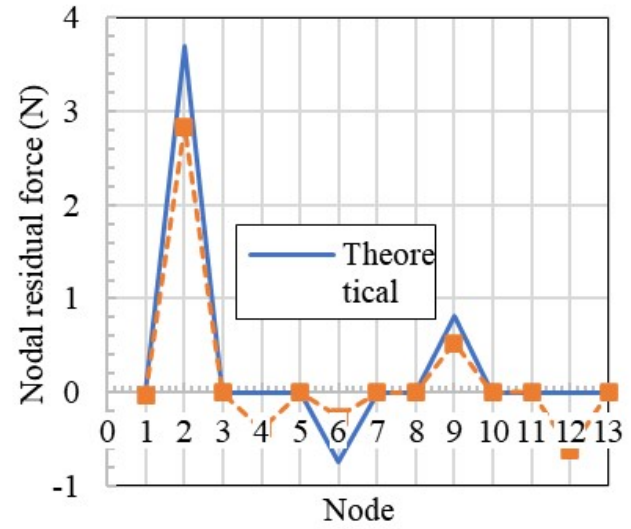

(a)

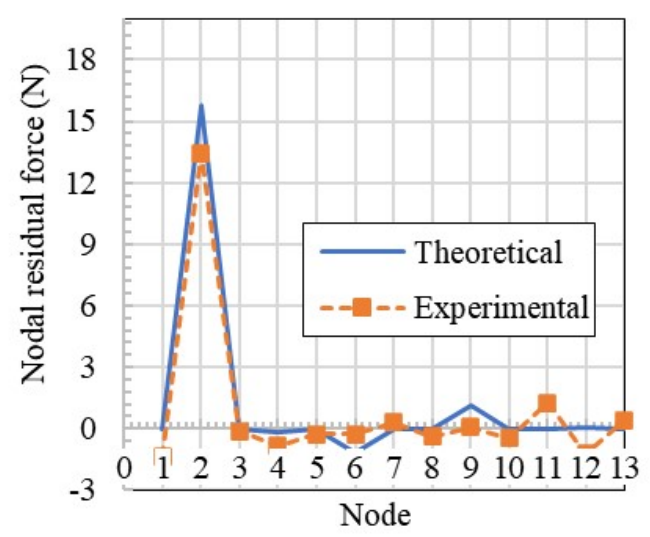

(b)

Figure 15: Residual nodal forces Imbalance $m_{2}$ at (a) $7500 \mathrm{rpm}$ (b) $15 \mathrm{Kprm}$

Table 2: Numerical and Experimental nodal residual force R-square results.

\begin{tabular}{cccc}
\cline { 3 - 4 } & & \multicolumn{2}{c}{ Test speed (rpm) } \\
\hline $\mathrm{S} / \mathrm{N}$ & TC Fault & 7500 & 15000 \\
\hline 1 & M1 Imbalance & 0.82 & 0.92 \\
\hline 2 & M2 Imbalance & 0.89 & 0.91 \\
\hline
\end{tabular}

\section{Conclusions}

An imbalance fault model was developed for the turbocharger rotor system that had the capability to determine the effect of changes of physical parameters on the turbocharger performance.

The fault models developed for the TC rotor system have been Tested and evaluated. Using Modal Expansion technique, data from nodal residual forces generated from the developed FEM fault model for Imbalance shaft fault, was compared with the experimental nodal residual forces data obtained from TC shaft induced with an Imbalance fault. As demonstrated by the Coefficient of Determination analysis (see Table 2), the results showed good agreement between the theoretical and experimental findings. Hence, the Model based fault identification 
scheme implemented in this study identified successfully the magnitude and exact location of an Imbalance fault on the TC shaft.

\section{References}

Adamkiewicz, A. and Michalec, G. (2000) 'General Diagnostic Model of a Marine Diesel Engine. Turbocharger', Marine Technology Transaction, 11, pp. 22-40.

Algule, S. R. and Hujare, D. P. (2015) 'Experimental Study of Imbalance in Shaft Rotor System Using Vibration Signature Analysis', International Journal of Emerging Engineering Research and Technology, 3, pp. 124-130.

Das, A. S. and Dutt, J. K. (2008) 'Reduced model of a rotor-shaft system using modified SEREP', Mechanics Research Communications, 35(6). doi: 10.1016/j.mechrescom.2008.04.004.

Devore, J. L. (2012) Probability and Statistics for Engineering and the Sciences. Boston, MA: Cengage Learning. Eling, R. (2018) Towards robust design optimization of automotive turbocharger rotor-bearing systems. $\mathrm{PhD}$ thesis, Delft University of Technology.

Jalan, A. K. (2013) 'Model based fault diagnosis of a rotor bearing system: Crack versus unbalance', in 10th International Conference on Condition Monitoring and Machinery Failure Prevention Technologies 2013, CM 2013 and MFPT 2013.

Loparo, K. A., Falah, A. H. and Adams, M. L. (2003) 'Model-based fault detection and diagnosis in rotating machinery', in Proceedings of the Tenth International Congress on Sound and Vibration.

Mayes, I. and Penny, J. E. T. (1998) 'Model-based diagnostics of faults in rotating machines', in Proc. of the 12th Int. Congress on Condition Monitoring and Diagnostic Engineering Management, pp. 431-440.

Miller, J. K. (2008) Turbo: Real world high-performance turbocharger systems. CarTech Inc.

Nembhard, A. D. et al. (2014) 'Combined vibration and thermal analysis for the condition monitoring of rotating machinery’, Structural Health Monitoring, 13(3). doi: 10.1177/1475921714522843.

Rahul, D. M. and Gupta, M. M. (2014) 'Vibration based condition monitoring by using Fast Fourier Transform (FFT)', International Journal of Engineering Research and Applications (IJERA), 31, pp. 2248-9622.

Ruhl, R. L. and Booker, J. F. (1972) 'A finite element model for distributed parameter turborotor systems', Journal of Manufacturing Science and Engineering, Transactions of the ASME, 94(1). doi: 10.1115/1.3428101.

Schweizer, B. (2010) 'Dynamics and stability of turbocharger rotors', Archive of Applied Mechanics, 80(9). doi: 10.1007/s00419-009-0331-0.

Sharma, R. S., Dewan, L. and Chatterji, S. (2015) 'Fault Diagnosis Methods in Dynamic Systems: A Review', International Journal of Electronics and Electrical Engineering, 3(6). doi: 10.12720/ijeee.3.6.465-471.

Wakiru, J. et al. (2018) 'Maintenance Optimization: Application of Remanufacturing and Repair Strategies', in Procedia CIRP. doi: 10.1016/j.procir.2017.11.008.

Zhang, H. (2012) Model Development and Stability Analysis for a Turbocharger Rotor System under Multi-Field Coupled Forces. Phd thesis, University of Huddersfield.

Zhao, W. et al. (2019) 'A novel method for identifying crack and shaft misalignment faults in rotor systems under noisy environments based on CNN', Sensors (Switzerland), 19(23). doi: 10.3390/s19235158. 